\title{
Thirty years in hemostasis research in Cluj Napoca
}

\author{
Mircea Cucuianu
}

\author{
University of Medicine and Pharmacy Iuliu Hatieganu, Cluj Napoca
}

\begin{abstract}
During the last 30 years, researchers from the Clinical Chemistry department of The University of Medicine and Pharmacy of Cluj Napoca were interested in elucidating the pathogenetic mechanisms responsable for thrombotic events in patients with atherosclerosis, and in implementing laboratory tests able to detect rare hemostasis abnormalities.

The researchers in Cluj brought arguments for the fact that abdominal obesity, (very susceptible to adrenergic stimulation) favors an accelerated lipolysis. This in its turn results in a massive secretion of free fatty acids which reach liver through the portal vein and stimulate the synthesis of VLDL incorporated triglycerides, as well as the production of hepatic proteins, such as fibrinolysis inhibitors (1). This mechanism also produces an increase of plasmatic level of coagulation FXIII, thus contributing to an increased resistance of the fibrin mesh to plasmin's proteolytic action (2).

Inflammatory processes accompanying atherosclerosis perturbate the anticoagulant mechanisms (3), whereas the protein $\mathrm{C}$ system exerts not only anticoagulant effects but also diminishes inflammatory processes (4). These findings are cited by Karnsakul W et al, Mikstowicz V et al and Mc Kenzie JA et al (5-7).
\end{abstract}

According to clinical observation and laboratory data it was considered that the increase of plasmatic level of von Willebrand factor in patients with myocardial infarction is more likely a consequence of the reaction of endothelial cells to adrenergic and proinflammatory stimuli, rather than a simple leakage of vWF from injured endothelia (8). This interpretation is accepted and cited by many authors such as Schorer et al (9), Pottinger et al (10)

It is worth mentioning that some genetic hemostasis defects were detected by the research group in Cluj Napoca.

Several cases of von Willebrand disease (with impaired response to ristocetin) were described, as well as a case of Glanzmann's thrombasthenia, with severely impaired platelet aggregation when stimulated by various agonists, including ADP (11).

A young man displaying a severe and prolongated bleeding after a dental extraction was investigated and diagnosed with an $\alpha 2$ plasmin inhibitor deficiency ( $\alpha 2 \mathrm{PI})$, this defect being associated with a quick clot lysis. The patient's father had the same deficiency, but being obese, and thus having an enhanced level of plasminogen activator inhibitor (PAI) did not display any bleeding disorders (12).

*Corresponding author: Mircea Cucuianu, University of Medicine and Pharmacy Iuliu Hatieganu, Cluj Napoca; e-mail: cucuianum@yahoo.com 
Several cases of antithrombin genetic deficiency were also detected, including cases with heparin-binding site alteration (13).

A heterozygous protein $\mathrm{C}$ deficiency was detected in a woman displaying a coumarin-induced skin necrosis (14), this case being cited by Seyfarth HJ et al (15). These cases were also included in the volume Hemostaza - Biochimie, fiziopatologie, clinică (16).

\section{References}

1. Brudaşcă I, Cucuianu M. Pathogenic role of abnormal fatty acids and adipokines in the portal flow. Relevance for metabolic syndrome, hepatic steatosis and steatohepatitis. Rom J Intern Med. 2007;45(2):149-57.

2. Cucuianu M, Brudaşcă I. Coagulation factor XIII, impaired fibrinolysis and cardiovascular disease. Rev Romana Med Lab. 2011;19(2):119-27.

3. Brudaşcă I, Cucuianu M. Anticoagulant mechanisms are modulated by vascular endothelial cells. Rev Romana Med Lab. 2010;18(3):7-14.

4. Cucuianu M, Brudașcă I, Pleșca L, Bodizs G, Colhon D, Cucuianu A. Reciprocal antagonism between inflammation and the protein C system. Rev Romana Med Lab. 2013;21(2):129-33. DOI: 10.2478/rrlm2013-0003

5. Karnsakul W, Gillespie S, Skitarelic K, Hummel M. Obesity and Reversed Growth Retardation in a Child with Type Ia Glycogen Storage Disease. J Pediatric Endocrinol and Metabolism. 2010;23(5):507-12. DOI: 10.1515/jpem.2010.083

6. Mikstowicz V, Lucero D, Zago V, Cacciagiu L, Lopez $\mathrm{G}$, Gonzalez E, et al. Hepatic lipase activity is increased in non-alcoholic fatty liver disease beyond insulin resistance. Diabetes Metab Res Rev. 2012;28(6):535-41 DOI: $10.1002 /$ dmrr.2312
7. MacKenzie JA, Roosa KA, Gump BB, Dumas AK, Bendinskas KG. Plasma prekallikrein levels are positively associated with circulating lipid levels and the metabolic syndrome in children. Appl Physiol Nutr Metab. 2010;35(4):518-25. DOI: 10.1139/H10-039

8. Cucuianu M, Missits I, Olinic N, Roman S. Increased ristocetin-cofactor in acute myocardial infarction. Thromb Haemost. 1980;43:41-4.

9. Schorer AE, Moldow CF, Rick ME. Interleukin 1 or endotoxin increase the release of von Willebrand factor from human endothelial cells. Brit J Haematol. 1987;67:192-7. DOI: 10.1111/j.1365-2141.1987. tb02326.x

10. Pottinger BE, Read RC, Paleolog EM, Higgins PG, Pearson JD. von Willebrand factor is an acute phase reactant in man. Thromb Res. 1989;53(4):387-94. DOI: 10.1016/0049-3848(89)90317-4

11. Trif I, Pop E, Cucuianu M, Belciug L. Thrombastenia Glanzmann. Clujul medical. 1991;64:49-54.

12. Cucuianu M, Crâsnic, Knauer O, Roman S. Severe bleeding in $\alpha 2$ plasmin inhibitor deficiency. Rev Roum Biochim. 1989;26:273-7.

13. Cucuianu M, Comes L, Roman S, Boeru A. Antithrombin deficiency in a Romanian family. Pathogenic role of concomitently increased plasma level of clotting factors VII and X. Rev Roum Med Int. 1984;22:13-17.

14. Cucuianu M, Hagău N, Cotul S, Cardan E, Giurgea I. Heterozyhgous protein $\mathrm{C}$ deficiency and coumarin necrosis of the skin. Rom Journ Int Med. 1992;30(2):10511.

15. Seyfarth HJ, Siegemund A, Helling L, Woinke M, Pfeiffer D, Rühlmann C. Recurrent coumarin necrosis in type II protein S deficiency. Vasa. 2001;30(1):72-5. DOI: 10.1024/0301-1526.30.1.72

16. Cucuianu M, Trif I, Cucuianu A. Hemostaza - Biochimie, fiziopatologie, clinică. Editura Dacia Cluj Napoca, 1994. 